\title{
Independent Active and Reactive Power Control for Single Stage H8 Transformer-less Solar PV Inverter
}

DOI:10.36909/jer.10671

\author{
D.V.N.Ananth*, L.V. Sursh Kumar**, D.A. Tatajee*** \\ * D.V.N.Ananth, Department of EEE, Raghu Institute of Technology, Thagarapuvalasa, \\ Visakhapatnam-531126, Visakhapatnam Dist,India \\ ** L.V. Suresh Kumar, Department of EEE, GMR Institute of Technology, GMR Nagar, Rajam- \\ 532127, Srikakulam Dist,India \\ *** D.A. Tatajee, Sr. Software Engineer, Incedo Inc., Chennai,India
}

\begin{abstract}
With the rapid development in power electronics technologies and solar photovoltaic (PV) cells, the interest in solar PV cell-based electric power generation and other applications is increasing more incredibly. For low power grid or direct load applications, single-stage solar PV inverters without transformers are advantageous. Based on this concept solar single-stage eight switch H8 based transformerless solar PV inverter is proposed. The objective of the work is to present a control scheme for the H8 inverter to have better power handling capability and for independent active and reactive power control. For this, the test system is studied using MATLAB/ SIMULINK software under three cases (i) constant active power and varying reactive power, (ii) varying active power and constant reactive power, and (iii) varying both active and reactive power. The proposed inverter is compared with single-stage solar PV with two switches boost and six switches inverter topology. It is found that power flow ripples and surges are lesser for proposed H8 than with single-stage topology.
\end{abstract}

Keywords - Transformer-less solar PV inverter, H8 topology, independent active and reactive power flows

\section{Introduction}

With the rapid advancements and research in power electronics and renewable energy resources, the interest in the solar (photovoltaic) PV cell is increasing at a very high pace. This solar PV cell is used in all developing and developed countries with the scope of use in a meager rating of few watts to megawatts applications like toys, electronic boards, lighting and traffic control systems, electric 
vehicle charging, and power generation to power generation nearby industrial loads of few MWs. Based on global wind energy organization statistics, China, the USA, and India are the three top countries in the world to generate more than 10,000 MW of solar power by March 2018 [1]. China produced a total of $43.5 \mathrm{GW}$ in 2015 , while it increased to $78 \mathrm{GW}, 131 \mathrm{GW}$, and $175 \mathrm{GW}$ in 2016,17 , and 2018 years respectively, with a growth of 3\%. Similarly, the German growth rate by the end of 2018 is $7.9 \%$, Italy $7.3 \%$, Japan $6.8 \%$, and India it is $5.4 \%$. The solar panels' average efficiency commercially available in 2010 was around $12.2 \%$. It reached $15 \%$ in 2015 and is now, by the 2018 year-end is $20 \%$.

Over the last five years, significant development of direct connection of solar power which is dc is connected to ac grid using single or multi-stage conversions. Solar connection to grid or isolated grid multi-stage is beneficial for significant ratings, but losses and cost will be higher. But, single-stage conversion is advantageous for limited power ratings in terms of efficiency, controllability, reliability, and price. Single-stage solar PV inverters have different types: step-down, step-up, mixed configuration, resonant, impedance source converter, six switch, and transformer-less type topologies. The step-down design is of two topologies like buck-derived multilevel SSPCs and high-performance buck-natured configuration. This step-down configuration is unidirectional, with four to six switches with inductors or a transformer for voltage control [2-7]. Among all the step-down topologies, dualbuck is most preferred due to high efficiency, low harmonics generated, and lower cost due to passive components. The step-up single-stage PV inverter has two configurations, namely boost and buckboost [8-10]. This step-up converter generally contains four switches with a coupled inductor or a transformer for voltage level increasing. Among these, buck-boost is more attractive due to voltage increase or decrease capability. Also, drop due to leakage inductance is less, higher efficiency and robust control of both active and reactive power are advantages. Mixed single-stage converters like zeta, cuk, and flying inductor $[11,12]$ are also famous as both step up and step down configurations will be used. Compared to buck-boost, these also have better performance with lesser losses and lesser passive components. These mixed configurations are developed with and without transformers. 
The resonant single-stage inverters use 2 to 4 switches with inductor and capacitor ( $\mathrm{L}$ and $\mathrm{C}$ ) combination with an objective of voltage boosting capability [13-14]. These single-stage resonant inverters are developed based on half-bridge and full-bridge topologies with the $\mathrm{L}$ and $\mathrm{C}$ charging ad discharging control based on switching techniques to boost and maintain the desired voltage at the connecting point. Zero voltage and zero current switchings are widely adopted switching techniques with an advantage of minimum switching losses: further high-frequency operation, higher reliability, better efficiency, and less electromagnetic interference. In the early stages around 2006, Z-source impedance inverters were popular. But, the large inductor and capacitor with size, cooling, and losses made it look for advancements, so quasi z-source inverter topology is famous. With almost the same voltage gain and reduced stress on inductor and capacitor with adequate control of inrush starting possession and use of diodes makes this quasi z-source inverter prominent [15-18]. The number of switches is 4 to 8 based on voltage boosting capability and current carrying capacity. A six switch topology [19-20] is used for solar PV inverter to buck or increase the voltage to meet the grid voltage level with a smaller design. Isolated and non-isolated six switch models are available. The review papers [21-26] give good information about different transformer-less configurations known in the literature.

Based on the literature survey, there are few challenges faced by single-stage transformerless solar-PV cell inverters that need to be overcome for better performance.

i. They constrained power handling of the inverter and independent switching control capability.

ii. Power output characteristics are vastly varying in nature.

iii. Range of operation constrained due to imposed dc source.

iv. With an increase in power handling capability, the price of the inverter set increases considerably.

v. An increase in the power handling capability results in high peak current stress.

vi. Few Maximum Power Point Tracking (MPPT) techniques are applicable as there is no intermediate chopper circuit. 
Based on these disadvantages, the interest towards multi-stage is increasing by compromising the number of switches, efficiency, and weight of the inverter panel compared to a single-stage inverter. Suppose these challenges are met to a certain extent. In that case, there can be a significant advance in the solar PV topology applicable to rooftop household applications, hybrid electric vehicles, and other applications. Based on the author's knowledge, there is no paper on transformerless solar PV inverter that describes the power flow control capability. Most of the report deals with switching strategies, efficiency improvement, and modulation techniques.

Hence, this paper is developed to consider power handling and independent active and reactive power flow controlling capability using a conventional H8 topology single-stage transformerless solarPV cell inverter [27]. Here, the output from solar PV panel is directly connected to the eight switch inverter and is connected to a medium power rating grid directly. It has good power output characteristics and reduced current stress for the exact cost of conventional H8 topology. The control scheme is developed with good current-carrying and voltage regulating aspects, defined power-factor, and independent active and reactive power flow control. A single-stage solar PV inverter with chopper inverter configuration with $\mathrm{P} \& \mathrm{O}$ MPPT and reactive power flow control is discussed in the very recent article [28].

Section II describes the control strategy for independent active and reactive power flow. Section III explains the switching pattern of the H8 inverter in detail. Section IV of this paper discusses the topology of the H8 test system. Results and discussions are demonstrated in section $\mathrm{V}$ for the test system under three cases like (i) constant active power and varying reactive power, (ii) varying active power and constant reactive power and (ii) varying both active and reactive power. A comparison of the proposed topology and controller with a single-stage three-phase solar-PV inverter with a chopper [28] is discussed in this paper. Finally, section VI concludes the work followed by appending showing the system's parameters and then the references. 


\section{Control strategy for independent active and reactive power flow}

In this section, stationary dq frame reference-based current are derived at the inverter side before and after the filter. The relation of LCL filter elements with equivalent parameters is shown analytically. The rate of change is represented as $\rho$, as shown below.

$$
\rho=\frac{d}{d t}
$$

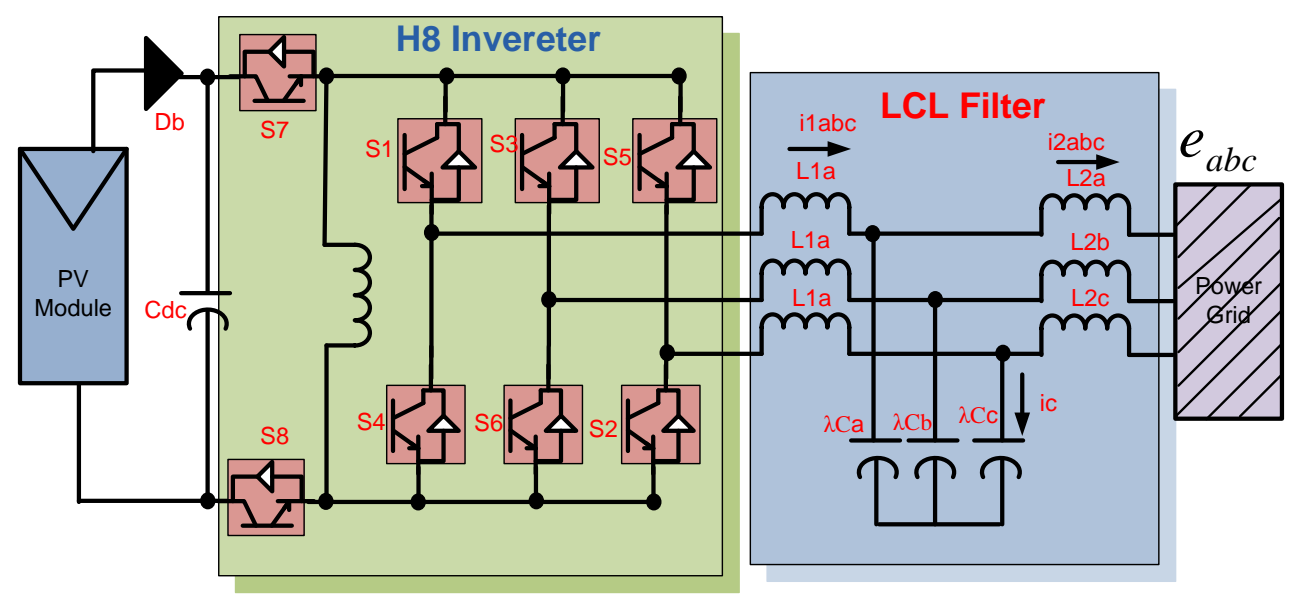

Fig.1 H8 based solar-PV inverter topology with LCL filter

Fig. 1 is considered for the analysis. Here L1 and R1 represent the LCL filter towards the inverter end inductance parameters, and L2 and R2 represent the inductor's grid side part with its internal resistance. So, one here represents the inverter end part of the variable, and 2 illustrates the grid side variables or measurable parameters. The $\mathrm{H} 8$ inverter configuration working principle is explained in [27]. Here, the converter output voltage before the filter and the filter capacitor voltage are represented in output current and voltage after the filter. Also, the LCL filter's equivalent resistance and inductance shown in the Fig. 1 are having internal element values specified in terms of $R_{1}, R_{2}, L_{1}, L_{2}$ and $C$.

The logic for the control circuit is described here. It will have four control loops, with outer control loops controlling the real and reactive powers and the internal loops controlling the currents. The real power loop will produce the direct (d) axis current reference and the reactive power loop will produce the quadrature axis current reference. The real power flow optimal power is derived using lookup table as optimal reference power and the actual power are compared and will produce an error. 
This power error is minimized and maintained nearly at zero value by using power controller loop which is a PI controller with Kpn and Kin as proportional and integral gain parameters. The output from the tuned PI controller will get reference d-axis current (Id). The error in reference and actual reactive power give reference direct axis current (Iq). The difference between these reference and actual two axis currents is controlled by tuned PI controller to get respective direct and quadrature axis voltages. The output from each PI controller is manipulated with disturbance voltages to get reference voltage for pulse generation. It must be noted that the pulses are regulated at slip frequency for RSC rather than at fundamental frequency and slip frequency synchronizing for inverse Park's transformation. The pulse generator will produce three number of pulses for the main switches S1, S3 and S5 for positive switches and with NOT gate for these positive switches produces switching signals S2, S4 and S6 as negative switches. With NAND gate for positive switches will produce pulses for S7 and NAND gate for negative switches will produce pulses for S8. So, for this, $\mathrm{d}$ and $\mathrm{q}$ axis current controls, dependency of the inverter real and reactive power flows, and the filter element components design and parameter dependencies will be discussed analytically in Sections 2 and 3 and modeling will be explained in Section4.

The dynamic dq axis current at the inverter terminal side in terms of capacitor voltage $(\mathrm{Vc})$ as given by equation (1) is

$$
L_{1} \rho i_{1 d q}=V_{d q_{-} c o n v}-V_{c d q}-R_{1} i_{1 d q}-\omega_{s} L_{1} i_{1 d q}
$$

Here, inverter side voltage is given by $\left(\mathrm{V}_{\mathrm{dq} \_ \text {conv }}\right)$, the filter capacitor voltage is $\left(\mathrm{V}_{\mathrm{cdq}}\right), \omega_{\mathrm{s}}$ is the angular frequency on the inverter end. The capacitor on the shunt side of the filter is represented as C here. So, the dynamic voltage of the filter capacitor in terms of input filter side current is $\left(i_{1 d q}\right)$, and the current passing through the filter capacitor is $\left(\mathrm{c}_{\mathrm{dq}}\right)$, and the voltage across this capacitor is $\left(\mathrm{e}_{\mathrm{dq}}\right)$ is represented by the equation $(2 a)$ is

$$
C \rho V_{c q}=i_{1 d q}-j \omega_{s} C e_{d q}-i_{c d q}
$$


The dynamic filter capacitor is represented in terms of capacitor voltage, and capacitor current is given by equation $(2 b)$

$$
L_{2} \rho i_{c d q}=e_{d q}-V_{c d q}-R_{2} i_{c d q}-j \omega_{s} L_{2} i_{c d q}
$$

The active power and reactive power flow at the filter input side terminal is given by equations (3a) and (3b), where ed and eq represents the grid side $\mathrm{d}$ and $\mathrm{q}$ axis voltages respectively.

$$
\begin{aligned}
& P=e_{d} i_{1 d}+e_{q} i_{1 q} \\
& Q=e_{q} i_{1 d}-e_{d} i_{1 d}
\end{aligned}
$$

Therefore, using the equations (3a) and (3b) to extract the $d$ and $q$ axis current at the filter input side current is given by the equations (4a) and (4b) as

$$
\begin{aligned}
& i_{1 d}=\frac{P e_{d}+Q e_{q}}{e_{d}^{2}+e_{q}^{2}} \\
& i_{1 q}=\frac{P e_{q}-Q e_{d}}{e_{d}^{2}+e_{q}^{2}}
\end{aligned}
$$

The $\mathrm{d}$ and $\mathrm{q}$ axis voltage balance across the inverter side inductor in terms of converter $\mathrm{d}$ and $\mathrm{q}$ axis voltages and filter input side current is given by the equations (5a) and (5b) is

$$
\begin{aligned}
& V_{c d}=R_{1} i_{1 d}+L_{1} \rho i_{1 d}-\omega_{s} L_{1} i_{1 q}+V_{d_{-} c o n v} \\
& V_{c q}=R_{1} i_{1 q}+L_{1} \rho i_{1 q}+\omega_{s} L_{1} i_{1 d}+V_{q_{-} c o n v}
\end{aligned}
$$

The balance across the grid side inductor in terms of $d$ and $q$ axis voltage in terms of filter output side $\mathrm{d}$ and $\mathrm{q}$ axis current and capacitor voltages is given by equations (6a) and (6b) is

$$
\begin{aligned}
& e_{d}=R_{2} i_{2 d}+L_{2} \rho i_{2 d}-\omega_{s} L_{2} i_{2 q}+V_{c d} \\
& e_{q}=R_{2} i_{2 q}+L_{2} \rho i_{2 q}+\omega_{s} L_{2} i_{2 d}+V_{c q}
\end{aligned}
$$

The LCL filter output current under current balance form is given by equation (7a) and (7b) is

$$
i_{2 d}=i_{1 d}+C \rho V_{c d}-C \omega_{s} V_{c q}
$$




$$
i_{2 q}=i_{1 q}+C \rho V_{c q}+C \omega_{s} V_{c d}
$$

The grid voltage in stationary dq frame in terms of output current from the filter entering the grid and the voltage across the capacitor in stationary dq axis is shown in equation (8)

$$
e_{d q}=R_{2} i_{2 d q}+L_{2} \rho i_{2 d q}+j \omega_{s} L_{2} i_{2 d q}+V_{c d q}
$$

The capacitor dq axis voltage can be represented in terms of filter input current and converter voltage as

$$
V_{c d q}=R_{1} i_{1 d q}+L_{1} \rho i_{1 d q}+j \omega_{s} L_{1} i_{1 d q}+V_{d q_{-} c o n v}
$$

The output filter current as a function of input current and capacitor voltage can be written as

$$
i_{2 d q}=i_{1 d q}+C \rho V_{c d q}+j \omega_{s} C V_{c d q}
$$

During the steady-state condition, the differential element $(\mathrm{P})$ becomes zero, so the equations (8 to 10) will become equations (11 to 13$)$ as

$$
\begin{aligned}
& e_{d q}=R_{2} i_{2 d q}+j \omega_{s} L_{2} i_{2 d q}+V_{c d q} \\
& V_{c d q}=R_{1} i_{1 d q}+j \omega_{s} L_{1} i_{1 d q}+V_{d q_{-} c o n v} \\
& i_{2 d q}=i_{1 d q}+j \omega_{s} C V_{c d q}
\end{aligned}
$$

Using equations (1), (2), and (9) in equation (13), the output filter current in stationary dq frame can be written in a simplified form as given by equation (14) as

$$
i_{2 d q}=\frac{L_{1}}{\left(L_{1}+L_{2}\right)}\left[\frac{-V_{q_{-} c o n v}}{j \omega_{s} L_{1}}+j\left(V_{d} j \omega_{s} C-\frac{\left(V_{d}-V_{d_{-} c o n v}\right)}{j \omega_{s} L_{1}}\right)\right]
$$

Upon solving equation (3a, 3b), and (5a, 5b) and representing the power flows in active and imaginary parts will give active power and reactive power supplied by the inverter is shown in equation (15a) and (15b) as

$$
P_{a c}=-\frac{e_{d} V_{q_{-} c o n v}}{j \omega_{s}\left(L_{1}+L_{2}\right)}=\frac{j e_{d} V_{q_{-} c o n v}}{\omega_{s}\left(L_{1}+L_{2}\right)}
$$




$$
Q_{a c}=\frac{e_{d}\left(e_{d}-V_{d_{-} c o n v}\right)}{j \omega_{s}\left(L_{1}+L_{2}\right)}-\frac{j \omega_{s} L_{1} C}{\left(L_{1}+L_{2}\right)} e_{d}^{2}
$$

The equations (15a) and (15b) are the active and reactive power supplied to the grid represented in grid voltage, inverter voltage, and LCL filter terminal parameters. The resonant frequency produced by the filter components as

$$
\text { Resonant frequency } f_{\text {res }}=\frac{1}{2 \pi} \sqrt{\frac{L_{1}+L_{2}}{C L_{1} L_{2}}}
$$

The converter dq axis voltage, capacitor voltage, and input filter current parameters are defined in converter and capacitor voltage parameters in the simplified form. The equation (9) can also be represented in terms of converter voltage, input filter currents as shown in equation (17) as

$$
V_{d q_{-} c o n v}=V_{c d q}-R_{1} i_{1 d q}-L_{1} \rho i_{1 d q}-j \omega_{s} L_{1} i_{1 d q}
$$

Similarly, equation (8) can be rewritten for capacitor dq axis voltage as given by equation (18)

$$
V_{c d q}=e_{d q}-R_{2} i_{2 d q}^{\prime}-L_{2} \rho i_{2 d q}^{\prime}-j \omega_{s} L_{2} i_{2 d q}^{\prime}
$$

Also equation (10) can be rewritten for the input current as given by equation (19)

$$
i_{1 d q}=i_{d q}^{\prime}-C \rho V_{c d q}-j \omega_{s} C V_{c d q}
$$

The equation (17) for the dq axis converter voltage can be simplified and written for individual $\mathrm{d}$ and $\mathrm{q}$ axis voltages are given by equations (20a) and (20b). They are substituting equations (18) and (19) in equation (17) and separating the active and imaginary parts to get $\mathrm{d}$ and $\mathrm{q}$ axis converter voltages. This converter voltage is in the simplified form and is represented in terms of output current and grid voltages.

$$
\begin{aligned}
& V_{d_{-} \text {conv }}=V_{2 d}\left(1-\omega_{s}^{2} L_{1} C\right)-R_{e q} i_{2 d}^{\prime}+\omega_{s} L_{e q} i_{2 q}^{\prime} \\
& V_{q_{-} \text {conv }}=V_{2 d}\left(R_{1} \omega_{s} C\right)-R_{e q} i_{2 q}^{\prime}-\omega_{s} L_{e q} i_{2 d}^{\prime}
\end{aligned}
$$

Using the equation $(18,19,20 \mathrm{a}$ and $20 \mathrm{~b})$, the capacitor $\mathrm{d}$ and $\mathrm{q}$ axis voltages is represented in the simplified form as output filter voltage as shown in equations (21a) and (21b) as 


$$
\begin{aligned}
& V_{c d}=V_{2 d}\left(1-\omega_{s}^{2} L_{1} C\right) \\
& V_{c q}=V_{2 d}\left(R_{1} \omega_{s} C\right)
\end{aligned}
$$

Upon using equations (17) to (20b), the equivalent resistance and inductance of the filter can be obtained in the simplest form containing only passive parameters is shown in equations (22a) and (22b)

$$
\begin{aligned}
& R_{e q}=R_{1}+R_{2}-R_{1} \omega_{s}^{2} L_{2} C-R_{2} \omega_{s}^{2} L_{1} C \\
& L_{e q}=L_{1}+L_{2}+R_{1} R_{2} C-\omega_{s}^{2} L_{1} L_{2} C
\end{aligned}
$$

Hence, as stated earlier, simplified inverter voltage equations and equivalent filter component values are derived. Next, the current control parameters and variables are derived as described in the next section.

\section{Design of current controller}

The current controller is the inner loop feedback closed-loop control, as shown in Fig.2b. The transfer function representation in terms of output current and voltage, which is after the filter. Using equations (10), (21a), (21b), and (18), the transfer function of output current is given by equations (23a and 23b) in terms of filter element parameters.

$$
G_{i 2}(s)=\frac{i_{2}(s)}{V_{o}(s)}=\frac{1}{s L_{2}}\left(\frac{K_{L C}^{2}}{s^{2}+\omega_{r e s}^{2}}\right)
$$

where the $\omega_{\text {res }}$ and $\mathrm{K}_{\mathrm{LC}}$ are shown below

$$
\omega_{\text {res }}=\sqrt{\frac{L_{1}+L_{2}}{C L_{1} L_{2}}} \text { and } K_{L C}=\frac{1}{\sqrt{L_{1} C}}
$$

Here, the $\omega_{\text {res }}$ represents the resonant angular frequency, KLC is the filter gain constant, and Vo is the output voltage after the filter, which is the same as $\mathrm{V}_{2}$. 
The filter capacitor transfer function is given in the capacitor current, and output voltage after the filter is shown in equation (24). The equations (2a), (2b), (21a) and (21b) help in obtaining the transfer function.

$$
\begin{aligned}
& G_{c}(s)=\frac{i_{c}(s)}{V_{o}(s)}=\frac{1}{s L c}\left(\frac{s^{2}}{s^{2}+\omega_{r e s}^{2}}\right)=\frac{1}{L c}\left(\frac{s}{s^{2}+\omega_{r e s}^{2}}\right)=\frac{G_{L C L}(s)}{K(s)+G_{L C L}(s)} \\
& K(s)=\frac{1}{L C}\left(\frac{s}{s^{2}+\frac{K_{i c}}{L C+\omega_{r e s}^{2}}}\right)
\end{aligned}
$$

The current gain is represented as the ratio of output current and capacitor current, as shown below in equation (25)

$$
\therefore \frac{i_{2}(s)}{i_{c}(s)}=\frac{G_{i 2}(s)}{G_{c}(s)}=\frac{K_{L C}^{2}}{s^{2}}
$$

This current gain is obtained easily by diving equations (23) and (24) with canceled output voltage. This gain is simply a function of the first filter inductor and its capacitor values and is a second-order function. Finally, the PI controller is defined in a conventional way as in equation (26a) with proportional and integral gain constants and Laplace coefficients'. $G_{P I}(s)=K \frac{s T_{i}+1}{s T_{i}}=K_{p}+\frac{K_{i}}{s}$

The proportional and integral gains represent the time constant of the first filter inductor and the capacitor, where the inductor time constant is expected to have at least nine times the capacitor time constant. Thereby proportional gain can also be derived as shown in equation (26b).

$$
K_{p}=-\left(\frac{L_{1}+L_{2}}{3 T_{C}}\right), T_{I}=9 T_{C} \text { and } T_{C}=\frac{1}{f_{c}}
$$

\section{H8 based solar PV transformer-less Inverter topology}

The proposed H8 based inverter topology for a grid-connected system with LCL filters is shown in Fig.1. In this, a solar PV inverter is used as an electrical power source, a conventional perturb \& 
Observe (P\&O) MPPT algorithm for extracting maximum power from the solar PV cell based on given irradiance and temperature. The switches S1 to S6 are connected as a conventional H-bridge inverter, and S7 and S8 are two switches connected to the dc-link side for boosting application to reach the voltage level of the grid. Hence, the inductor, S7 and S8 switches act like boost networks and adjustable voltage regulators. This configuration does not require a transformer to maintain the voltage to the grid level. The advantages of this H8 topology compared to a single-stage inverter with a chopper and a transformer are bidirectional voltage operation, lower leakage current, galvanic isolation, linear dc-ac voltage relationship, and lesser stresses on all the eight switches.

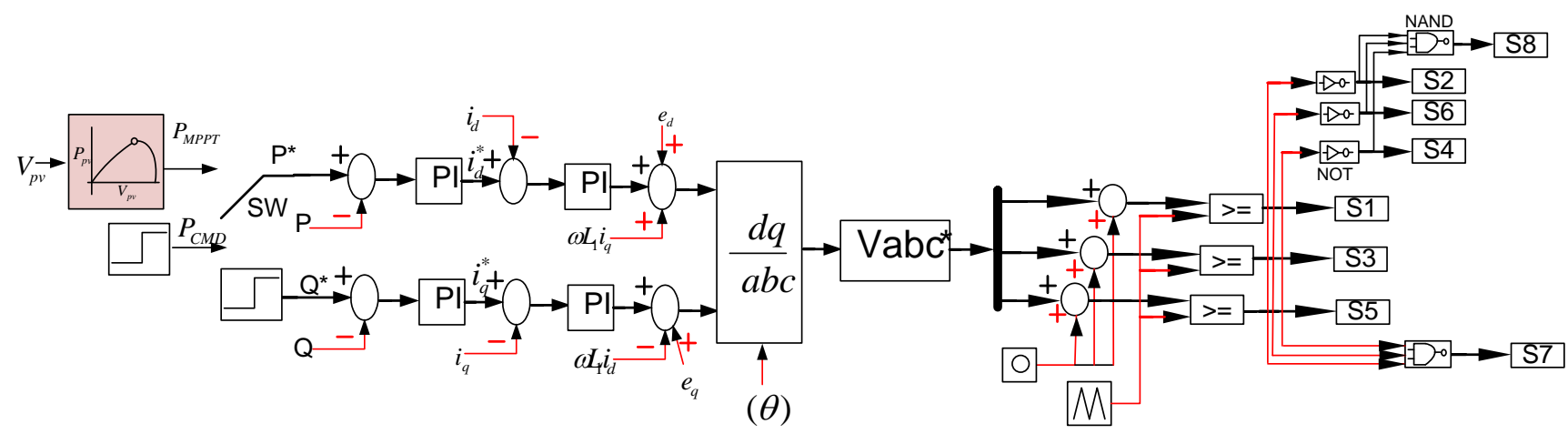

Fig.2(a) control strategy of grid connected solar-PV based H8 inverter with MDPWM technique

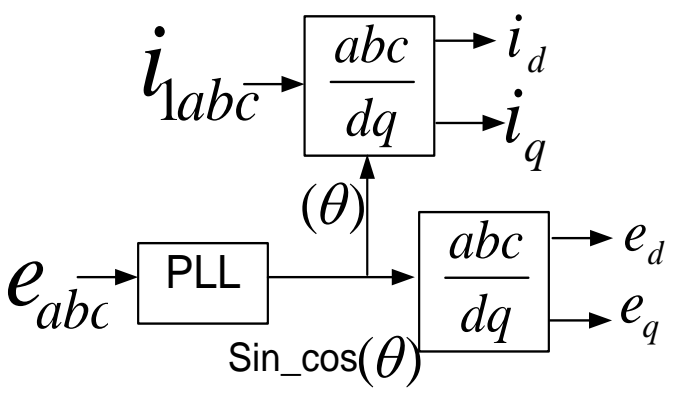

Fig. 2(b) $d$ and $q$ axis voltage and current extraction

The modified discontinuous pulse width modulation (MDPWM) strategy proposed in this paper is shown in Fig.2(a). The left side block with manual switch input combination is for open and closedloop feedback operations. The open-loop is done using a three-phase programmable generator, and the closed-loop is done using PV cell input and grid parameter requirement. The three-phase reference voltages from the closed-loop or open-loop are given to a demux block and are compared with either 
saw-tooth or triangular waveform. The triangular waveform has better characteristics observed from the simulation results used for the paper, but saw-tooth can also be used. After comparing with the carrier (triangle or saw-tooth), the three-phase reference voltages will produce three switching signals $\mathrm{S}_{1}, \mathrm{~S}_{3}$ and $\mathrm{S}_{5}$, for the respective switch numbers. A-phase voltage gives $\mathrm{S} 1$ and with not gate gives $\mathrm{S} 4$ switch pulse signal. Similarly, B-phase will give S3 and not produce an $\mathrm{S}_{6}$ switch signal, while Cphase gives $S_{5}$ and $S_{2}$ signals to the IGBT switches. The switches $S_{1}, S_{3}$, and $S_{5}$ signals are passed to the NAND gate to generate $S_{7}$ pulse signal and $S_{2}, S_{4}$ and $S_{6}$ switch pulse signals after passing through the NAND logic gate gives the $S_{8}$ pulse signal. The internal reference voltage waveform for the closed-loop operation will be done with this control circuit. The solar PV input reference voltage is given to the MPPT algorithm to provide the reference with maximum power output from the solar PV panel. So $\mathrm{P}_{\mathrm{mppt}}$ is obtained. If MPPT is not desired, a switching reference signal is given if the power generation value is to be changed. Both active powers can be selected using a manual switch selector. The reactive power flow control reference value can be adjusted to any desired value using a step signal. It will control the reactive power flow from or to the grid by the inverter. The reference and the actual active power in the outer control loop is compared, and the error signal is given to the PI controller, and the output from it is the d-axis reference current.

Similarly, with the difference between the reference and the actual reactive power flows, the error in the differences is controlled using another PI controller, and its output gives q-axis reactive reference current. These two $d$ and q axis reference currents are compared with actual inverter $d$ and $q$ axis currents and these two currents are given to another two well-tuned internal loop PI controllers. From each internal-loop PI controller, its output will be given to the $\mathrm{d}$ and $\mathrm{q}$ axis voltages. These voltages are added with decoupling parameters and disturbance or demagnetizing respective $\mathrm{d}$ and $\mathrm{q}$ axis voltages as shown in Fig.2(b). The vectorial summation of these voltages gives reference, $\mathrm{d}$ and $\mathrm{q}$ axis voltages. Using Park's transformation technique, these two stationary d and q axis voltages are transformed to reference abc voltages (Vabc*). The actual stationary two axis dq voltages $\left(\mathrm{e}_{\mathrm{d}}\right.$ and $\left.\mathrm{e}_{\mathrm{q}}\right)$ 
and currents $\left(i_{d}\right.$ and $i_{q}$ ) are extracted using Phase Locked Loop (PLL) are shown in the Fig.2(c). These voltages and currents are used in Fig,2(b) for the internal loop controlling.

\section{Result analysis}

This section compares a single-stage three-phase solar-PV inverter with capacitor storage [28] with the proposed H8 topology and control scheme. Three different cases are considered for the analysis. In the first case, constant active power and a rapidly changing reactive power. In the $2^{\text {nd }}$ case, reference change in both active and reactive powers, and in the last issue, there is reference change in active power with a constant reactive power signal. The irradiance is $1000 \mathrm{~W} / \mathrm{m}^{2}$, grid and inverter reference voltages are $440 \mathrm{~V}, 1 \mathrm{MW}$ power rating, $\mathrm{L} 1, \mathrm{~L} 2$ filter is $3.7 \mathrm{mH}$, Capacitance is $0.47 \mu \mathrm{F}$, input inductor is $330 \mu \mathrm{H}$, and IGBT switching is $10 \mathrm{kHZ}$.

Case 1: Constant active power and variable reactive power control

In this case, a reference power step-change in reactive power is given from $-0.7 \mathrm{pu}$ to $0 \mathrm{pu}$ at $0.05 \mathrm{~s}$. It is maintained constant $0 \mathrm{pu}$ till $0.1 \mathrm{~s}$ and then changed to $0.7 \mathrm{pu}$ at $0.1 \mathrm{~s}$. The grid voltage, grid current, and an inverter A-phase voltage and current are compared with a single-stage chopper-based solar-PV inverter shown in Fig.3(a), and with proposed, H8 based inverter is shown in Fig.3(b). In both the topologies, the grid voltage is constant, and the same with reactive power as grid parameters have higher power ratings. In this, the grid voltage and the inverter voltage ratings are the same, but the current rating of the grid is very high. With single-stage and the proposed topology, the current injected to the grid changes with reference reactive power change. At leading (-ve) pf and lagging pf, the current injected to the grid is higher than at unity pf. The difference in current injected is more significant with the proposed topology than with single-stage topology, as observed with the singlestage scheme. The A-phase voltage and current of the single-stage inverter [28] and H8 inverter are shown in the bottom figures of Fig. 3(a) and 3(b). 

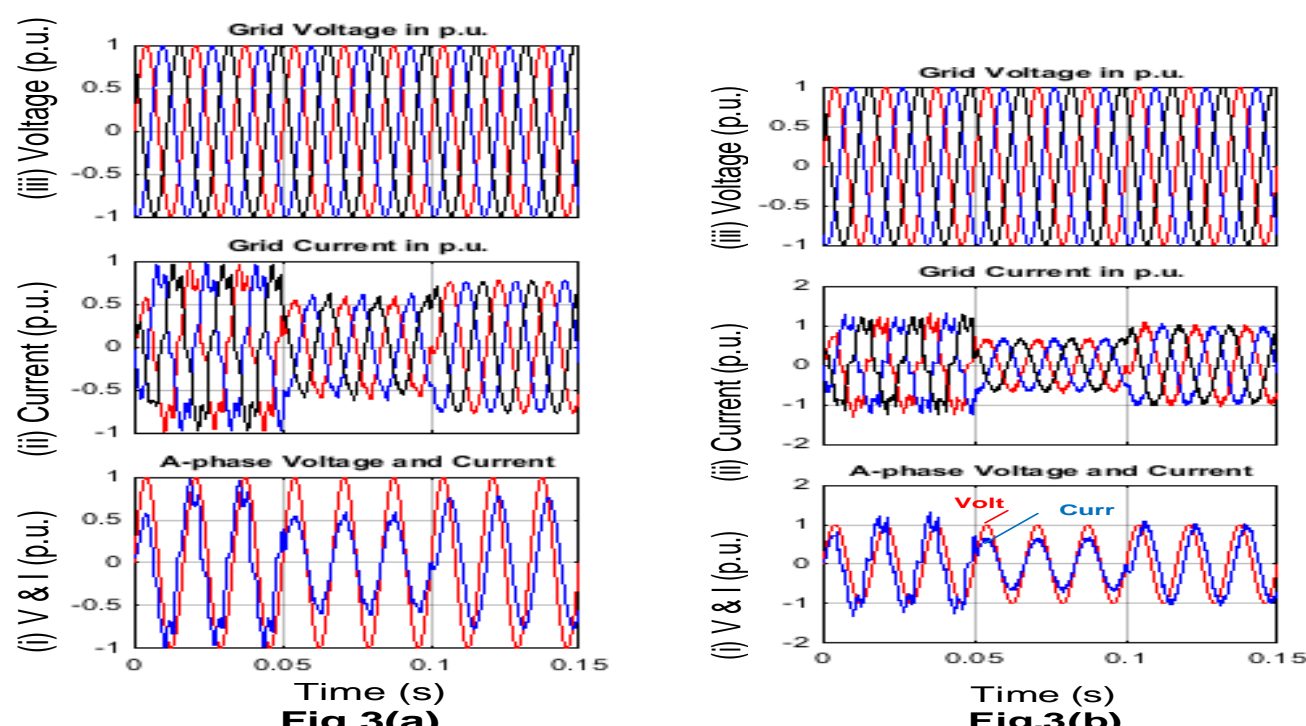

Fig. 3(a) Grid voltage, current and inverter voltage \& current with single-stage topology and

Fig.3(b) proposed configuration with constant active power and variable reactive power case.

The voltage and current levels reaching their final value are quicker with the proposed configuration in Fig.3(b) than single-stage in Fig. 3(a). Also, the unity power factor (0pu reactive) has more difference in the peak to peak values of voltage and current with single-stage than with the proposed during 0.05 to $0.1 \mathrm{~s}$. The red colour phase is Voltage and the blue colour phase waveform is current for the Fig. $3 a(i)$ and $3 b(\mathrm{i})$ for voltage and current $(\mathrm{pu})$. Further, during the lagging power factor (+ve reactive power), with both schemes, there is a phase shift in current to the right with both methods, but still, the current injection magnitude difference can be observed with a single-stage scheme than with the proposed. In the H8 configuration, the voltage and current are almost the same magnitudes when observed from 0.1 to 0.15 . However, voltage and current are not to the same extent with a single-stage scheme. Therefore, it can be observed that the output power is more with the proposed configuration than with single-stage topology. Hence, efficiency and controllability are higher as there are lesser leakage current losses in the inductor, the diode and IGBT losses are also more deficient with the proposed technique. As these losses are reduced, heat generation is also decreased, and hence overload and short circuit rating are also improved than with single-stage chopper-based inverter. 

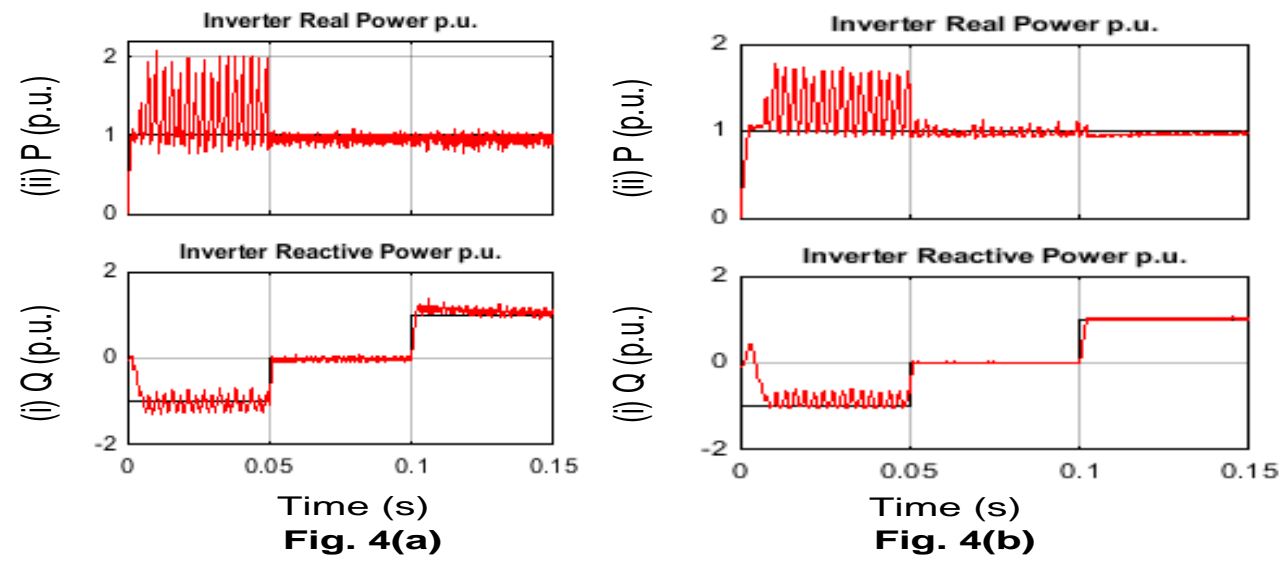

Fig.4(a) Inverter voltage \& current with single-stage topology and Fig.4(b) proposed configuration with constant active power and variable reactive power case

The active and reactive power flow from the inverter to the grid with single-stage topology is shown in Fig.4(a), and with proposed H8 topology is shown in Fig.4(b). It can be observed that the active power has more ripples at the leading power factor during 0.05 to $0.1 \mathrm{~s}$ with single-stage configuration than with the proposed design. The ripples are also higher under unity and lagging power factors with the single-stage scheme for active and reactive powers. The reactive power reference and actual values reached quickly and without ripples with the proposed configuration.

Case 2: Variable active and reactive power flow control

In this case, both active and reactive powers are changed in magnitude with time, and the results with single stage and proposed inverter topology are compared and shown in Fig. 5 and Fig.6. In this case, the active power is changed from 1 p.u. to 0 p.u. at $0.1 \mathrm{~s}$, and the reactive power is changed from 0 p.u. to 1 p.u. lagging step change at $0.05 \mathrm{~s}$. The grid voltage, current and overlapped waveform of inverter voltage and current with single-stage topology is shown in Fig. 5(a), and with proposed H8 topology is shown in Fig.5(b) and the H8 inverter waveform with THD characteristics is shown in Fig.5(c). It is observed that the grid voltage is constant, but the grid injecting currents vary as shown and are almost alike. When comparing the inverter current output with the single-stage and the 
proposed scheme, the current injected to the grid is higher with the proposed scheme as losses are lesser and with better controllability. The LC passive filters also play a major role in mitigating current harmonics and to improve power factor, but cannot improve voltage profile. The load voltage and current harmonics decreased by a greater factor using active filter and were restricted. Hence proposed control can be adopted and can be made utilized for improving voltage level near source and to decrease harmonic contents in the system. The control circuit for pulse generation is shown in figure 2 . In this source voltage is taken as reference to generate angles for phased locked loop. The real and reactive power is generated based on source voltage and current. Since the switches based inverted voltage and current will not be pure sinusoidal, the THD parameters plays a vital role. From these voltage and current parameters, real and reactive powers are calibrated. Using $2^{\text {nd }}$ order transfer function, we get compensating reference currents, the gain is used to get two axis currents. The feedback is used to get back compensating droop voltages. Further, two axis voltages are converted into three phase voltages and pulses to three phases are given independently using pulse width modulation (PWM) controller. The source current harmonics can be eliminated by using this method.
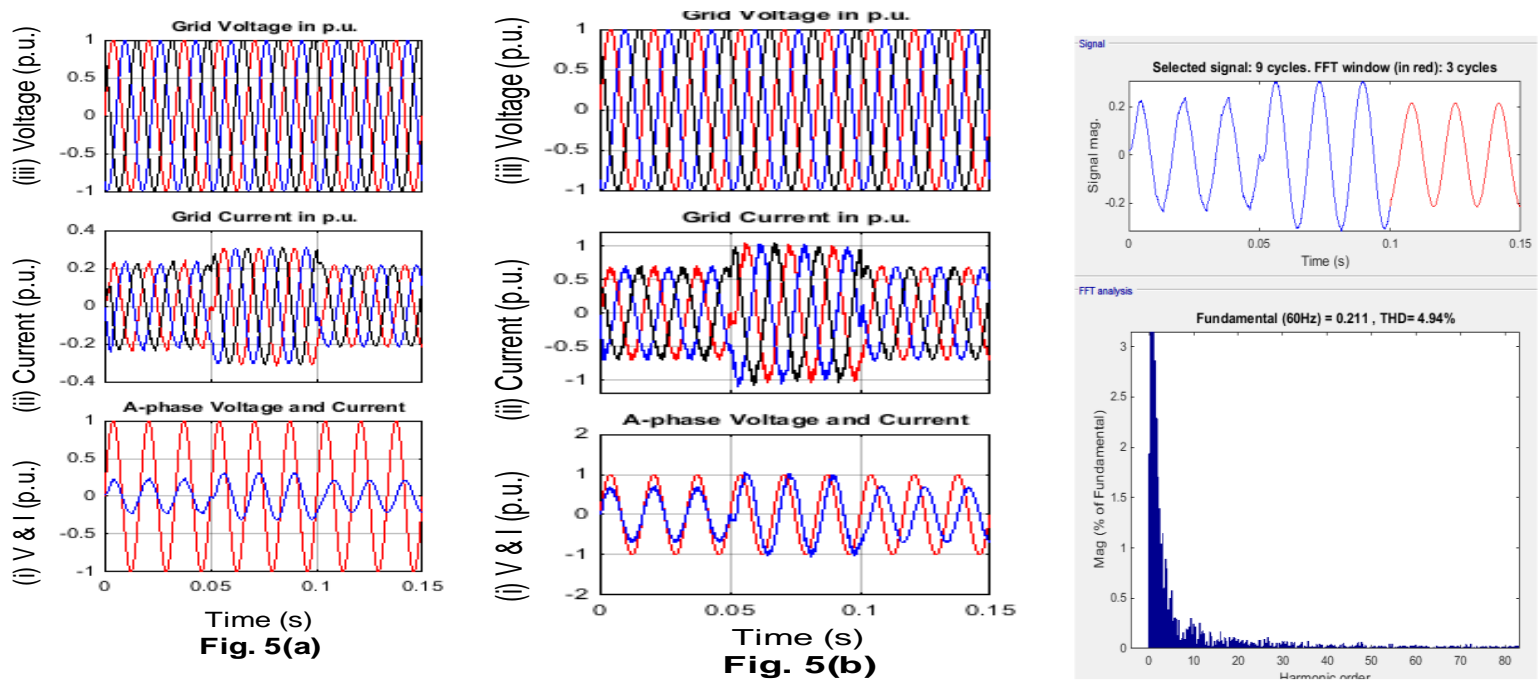

Fig. 5(a) Grid voltage, current and inverter voltage \& current with single-stage topology, Fig.5(b) proposed configuration and Fig. 5(c) THD of the current waveform with single-stage topology with variable active power and reactive power case 
The inverter voltage levels are almost the same with both configurations, but at unity pf, the single-stage current is $0.3 \mathrm{pu}$, whereas with proposed, it is $0.6 \mathrm{pu}$. With pure lagging load from 0.05 to $0.1 \mathrm{~s}$, the single-stage inverter current is $0.4 \mathrm{pu}$ and with $\mathrm{H} 8$ is $1 \mathrm{pu}$, and with phase-shift in the current can be observed with both cases. But, when the active power reference is suddenly made to 0pu, and the inverter supplies pure lagging unity reactive power from $0.1 \mathrm{pu}$, the current magnitude in both cases decreased instantly without any phase-shift in the current. The current with the single-stage scheme is $0.2 \mathrm{pu}$ and with $\mathrm{H} 8$ is $0.6 \mathrm{pu}$ and also, this time, the current injected to the grid is higher in value with the proposed topology. The current THD values are almost the same with both the cases with lesser than $5 \%$.

The inverter's active and reactive power flow to the grid waveforms using single-stage and proposed schemes are shown in Fig.6(a) and 6(b). The ripples in the active and reactive powers are high with single-stage topology, and these ripples are lesser with H8. But, the time taken to reach the final values of active and reactive power is comparatively slower with the present technique. However, the running performance is improved and is smoother and also the reference and actual values are almost the same. Hence the very accurate and better performance is expected with the $\mathrm{H} 8$ configuration. Due to the well-tuned LCL filter for ripple-free waveforms, better control strategy for smooth and effective operation.
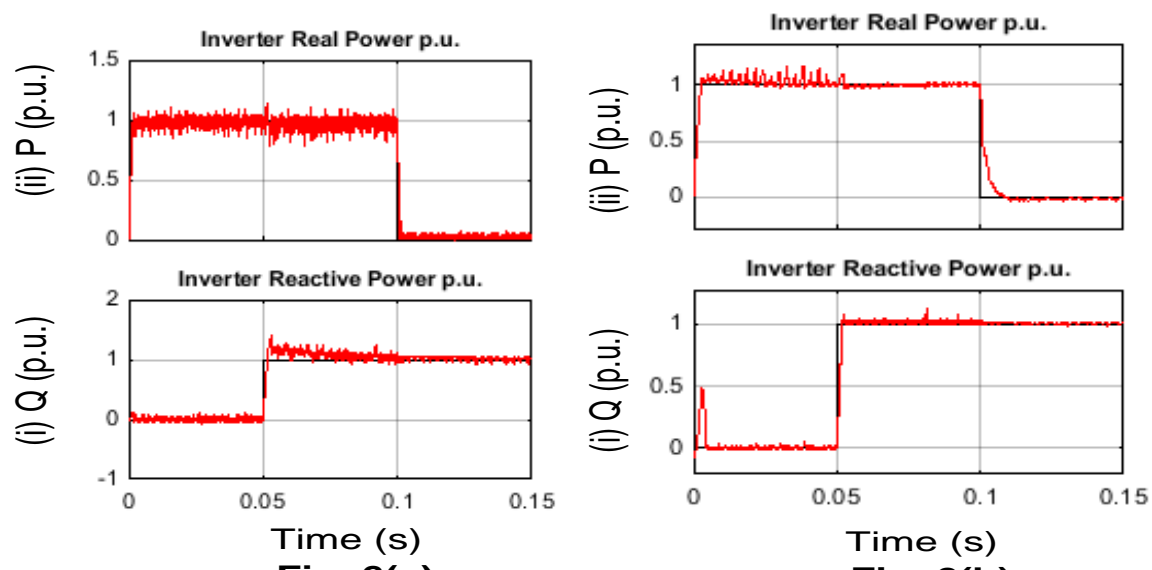

Fig. 6(a)

Fig. 6(b)

Fig.6(a) Inverter voltage \& current with single-stage topology and Fig.6(b) proposed configuration with variable active power and reactive power case 
Case 3: Constant reactive power and variable active power control

In the last case, only active power change is observed with no variation in reactive power command with active power change from unity per unit to $0.5 \mathrm{p} . \mathrm{u}$. at $0.05 \mathrm{~s}$ and finally changed to $0 \mathrm{pu}$ at $0.1 \mathrm{~s}$. The results are compared with single-stage and proposed topologies, as shown in Fig. 7 and 8 . The grid voltage is the same with both methods. However, the current to the grid is changing, as shown in Fig.7(a) and 7(b). The final value of the current is reached quickly at the starting instant 0 sec, and when the active power command is made zero, the current output from the inverter and getting the grid is almost zero with the proposed scheme. It is due to lesser switching and inductor losses and better controllability with the proposed control scheme. The inverter voltages are the same, but the current with $\mathrm{H} 8$ reached a minimum value when the active power flow command is made zero, and getting its final reference value is also quicker.
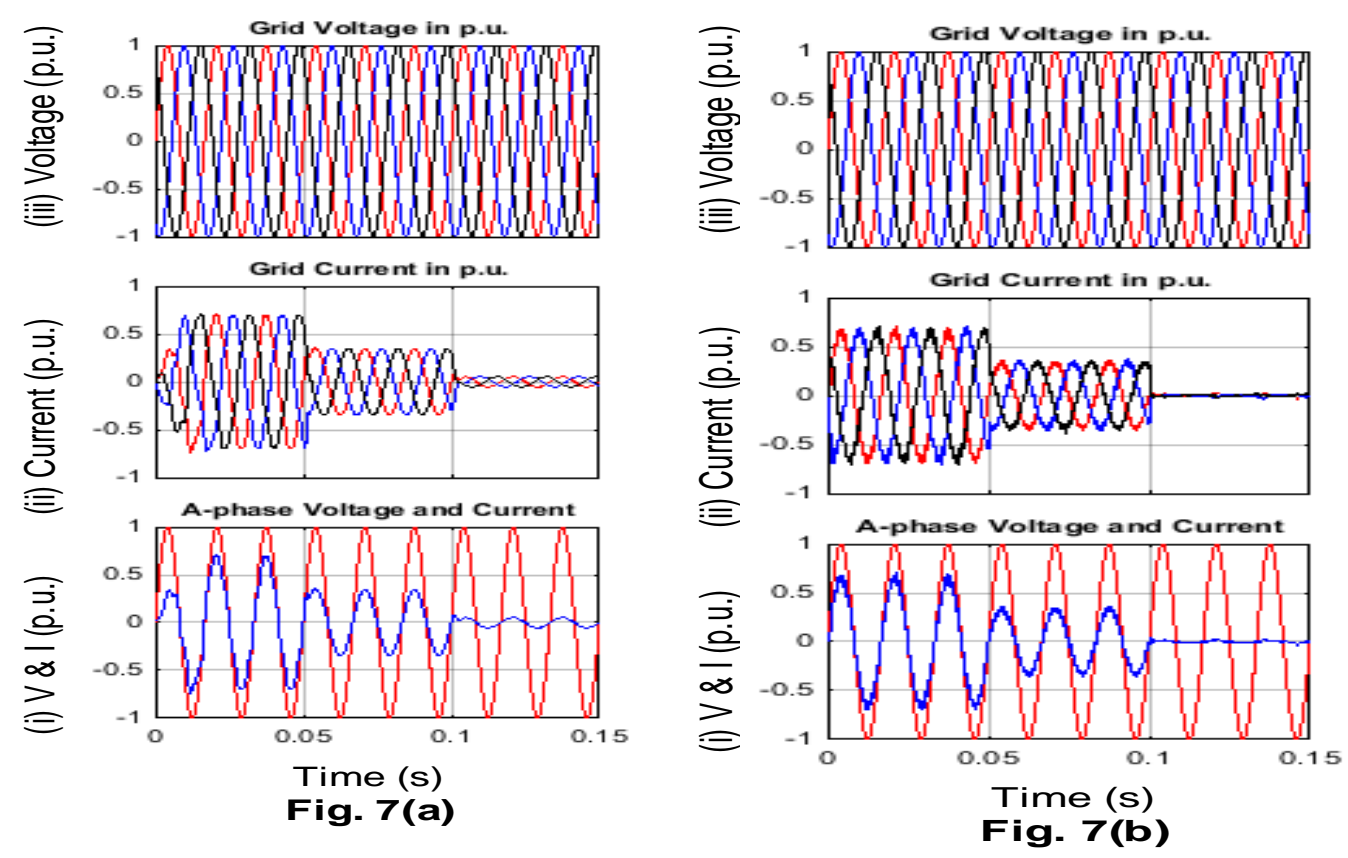

Fig. 7(a) Grid voltage, current and inverter voltage \& current with single-stage topology and

Fig.7(b) proposed configuration with constant reactive power and variable active power case

The active and the reactive power flow with the single-stage and proposed schemes are shown in Fig. 8 (a) and 8 (b). The time taken to reach its final active values is quicker and accurate with the $\mathrm{H} 8$ configuration. The ripples are relatively higher with $\mathrm{H} 8$, but the actual active power is following the 
reference command accurately. With a single-stage scheme, as shown in Fig.8(a), the active power command is $1 \mathrm{pu}$, which is slightly more than the value, and also when the control is made to $0.5 \mathrm{pu}$ in active power, there is some mismatch. But with lesser ripples and in the final stage where the active power demand is made to $0 \mathrm{pu}$, the active power is $0.15 \mathrm{pu}$ respectively and is not the reference value. Also, when full active power command is given, the reactive power has more ripples to overcome the switching and other reactive power demand to reach the values and sustain with the grid flows. This reactive power slowly became smaller values with the single-stage topology. With the H8 topology, the reference and actual commands in both active and reactive powers are met, and the active power ripples have small magnitude change. When the active reference power reference is changed to 0.5 or 0.0pu at 0.05 and $0.1 \mathrm{~s}$. This command will reach the $\mathrm{H} 8$ inverter terminal and a switching operation will be performed. This optimal switching operation helps in reducing the ripples in the current waveform. Thereby a decrease in the power change is observed. The reactive power ripples are less than $0.1 \mathrm{pu}$ with $\mathrm{H} 8$, while with single-stage is $0.25 \mathrm{pu}$ from 0 to $0.05 \mathrm{~s}$ and the ripples in reactive power are also decreasing gradually and are lesser than $0.05 \mathrm{pu}$ with H8 configuration. The discontinuous PWM technique, LCL filter characteristics and choice of H8 configuration are advantages of this method.

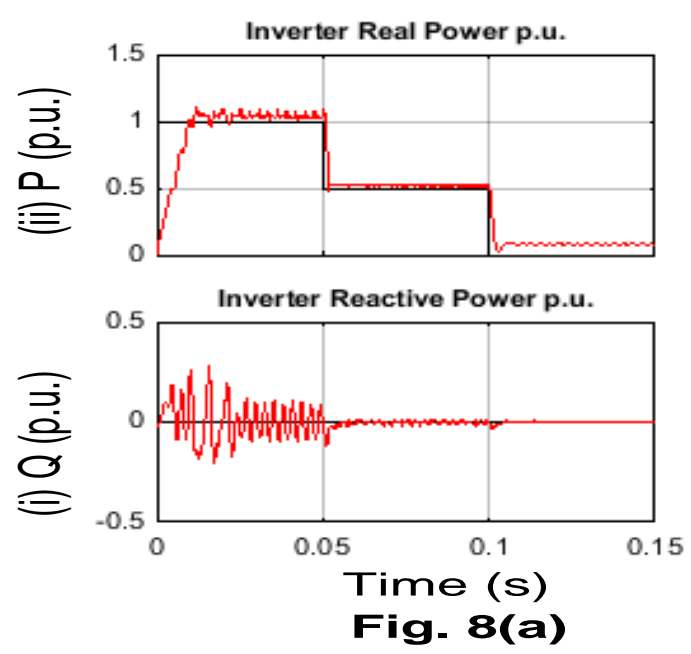

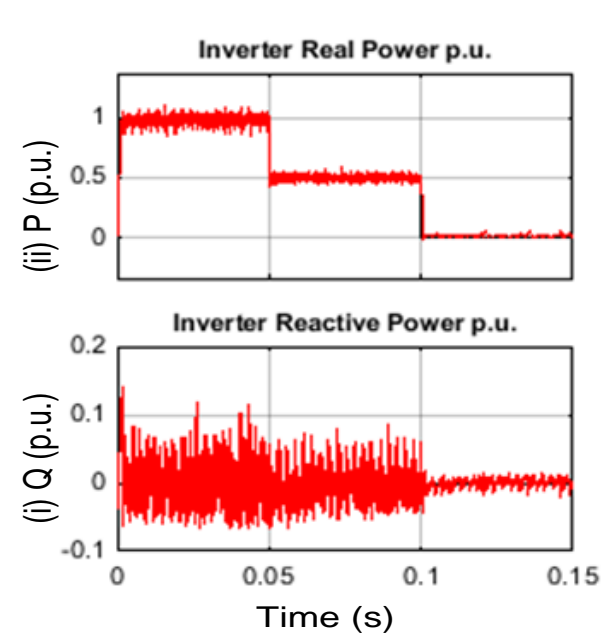

Fig. 8(b)

Fig.8(a) Inverter voltage \& current with single-stage topology and Fig.8(b) proposed configuration with constant reactive power and variable active power case 


\section{Conclusion}

The paper discusses the comparison of the proposed H8 configuration with a single-stage chopperinverter structure under three cases. The first case is with reactive power change and without active power flow change in command, in the second case with both changes in reference in both active and reactive power commands, and the third case with only active power reference or command change but constant reactive power command. The proposed configuration does not require a transformer, and the control strategy is simpler to adopt with any grid command changes. The advantages of the present system are lower inductive leakage losses, switching IGBT losses, and better LCL filter element combination. The ripples in active and reactive power are lesser, the final reach of actual value with the reference command is smoother, quicker, and more accurate with H8. The switching technique is the discontinuous PWM (DPWM) technique and eight IGBT switches. When zero active and reactive power command is given, the $\mathrm{H} 8$ reaches its accurate value with $\mathrm{H} 8$ with zero value in active and reactive powers, which is not done by the single-stage scheme.

Similarly, for the other active and reactive power schemes, accurate power commands are achieved. The current injected to the grid is more with the present topology as switching losses are lesser and lower leakage current flow. Hence, the present topology has advantages like better MPPT technique, independent active and reactive power flows, higher stress handling capability, lower source or grid side disturbance sensitivity, and applicability to a micro-grid connection.

\section{Appendix}

The PV array is simulated with dc voltage source of $600 \mathrm{~V}$. The stray capacitance $(C P V)$ is modeled with two capacitors of $220 \mathrm{nF}$, each connected between the PV terminal and the ground. The dc-link capacitor $(C D C)$ is $2 \mathrm{mF}$. The ground resistance $(R G)$ is $11 \Omega$. The filter is made up of three inductors $(L F)$; each has a value of $5 \mathrm{mH}$, capacitor $(\mathrm{Cf})$ is $2.2 \mathrm{nF}$. Grid frequency is $50 \mathrm{~Hz}$, nominal 
power is $2000 \mathrm{~W}$, phase grid voltage is $220 \mathrm{~V}$ (RMS), dc link voltage is $700 \mathrm{~V}$. Inudtor on inverter sie is $6.5 \mathrm{mH}$ and on grid side is $0.66 \mathrm{mH}$.

\section{References}

[1] https://www.worldenergy.org/data/resources/resource/solar/.

[2] Z. Aleem, S. Winberg, A. Iqbal, M. A. Al-Hitmi and M. Hanif, "Single-Phase Transformer based HF-Isolated Z- Source Inverters with Voltage Clamping Techniques for Solar PV Applications," in IEEE Transactions on Industrial Electronics, 2019, doi: 10.1109/TIE.2018.2889615.

[3] F. Hong, J. Liu, B. Ji, Y. Zhou, J. Wang, C. Wang, Single inductor dual buck full bridge inverter, IEEE Trans. Ind. Electron 62 (8) (2015) 4869e4877.

[4] Z. Yao, L. Xiao, Y. Yan, Dual-buck full-bridge inverter with hysteresis current control, IEEE Trans. Ind. Electron 56 (8) (2009) 3153e3160.

[5] L. Zhang, K. Sun, Y. Xing, J. Zhao, A family of five-level dual-buck full-bridge inverters for gridtied applications, IEEE Trans. Power Electron 31 (10) (2016) 7029e7042.

[6] Y. Cho, "Dual-buck residential photovoltaic inverter with a high-accuracy repetitive current controller," Renewable Energy, vol. 101, pp. 168-181, Feb. 2017.

[7] D.-H. Hwang, J.-Y. Lee, and Y. Cho, "Single-phase single-stage dual-buck photovoltaic inverter with active power decoupling strategy," Renewable Energy, vol. 126, pp. 454-464, Oct. 2018.

[8] Y. Zhou, J. Zhao, W. Huang, and P. Zhao, "High step-up single-stage boost inverter," 2011 IEEE Energy Conversion Congress and Exposition, Sep. 2011.

[9] J. Roy, Y. Xia and R. Ayyanar, "High Step-Up Transformerless Inverter for AC Module Applications With Active Power Decoupling," in IEEE Transactions on Industrial Electronics, vol. 66, no. 5, pp. 3891-3901, May 2019.

[10] D. Chen, Y. Qiu, Y. Chen and Y. He, "Nonlinear PWM-Controlled Single-Phase Boost Mode Grid-Connected Photovoltaic Inverter With Limited Storage Inductance Current," in IEEE Transactions on Power Electronics, vol. 32, no. 4, pp. 2717-2727, April 2017. 
[11] V. Gautam and P. Sensarma, "Design of Ćuk-Derived Transformerless CommonGrounded PV Microinverter in CCM,” IEEE Transactions on Industrial Electronics, vol. 64, no. 8, pp. 6245-6254, Aug. 2017.

[12] Schekulin, D. "Transformerless ac. inverter circuit for coupling photovoltaic systems or wind generator systems esp. in the low power range to current networks." German Patent DE19732218C1 (1999).

[13] Revana, Guruswamy, and Venkata Reddy Kota. "Simulation and Implementation of Resonant Controller Based PV Fed Cascaded Boost-converter Three Phase Five-Level Inverter System." Journal of King Saud University-Engineering Sciences (2019).

[14] Zhang, Shu-huai, Wang, Y.f., Chen, Bo, Xing, Wen-chao, Qiu, Han, 2016. An implementation of flexible topology strategy for an interleaved full-bridge LLC resonant converter in residential photovoltaic power systems. In: 2016 IEEE 8th International Power Electronics and Motion Control Conference (IPEMC-ECCE Asia), Hefei, 2016,pp. 3579-3585.

[15] M. Meraj, S. Rahman, A. Iqbal and L. Ben-Brahim, "Common Mode Voltage Reduction in a Single-Phase Quasi Z-Source Inverter for Transformerless Grid-Connected Solar PV Applications," in IEEE Journal of Emerging and Selected Topics in Power Electronics, vol. 7, no. 2, pp. 1352-1363, June 2019.

[16] B. Ge, F. Z. Peng, H. Abu-Rub, F. J. T. E. Ferreira and A. T. de Almeida, "Novel Energy Stored Single-Stage Photovoltaic Power System With Constant DC-Link Peak Voltage," in IEEE Transactions on Sustainable Energy, vol. 5, no. 1, pp. 28-36, Jan. 2014.

[17] S. Sajadian and R. Ahmadi, "Model Predictive-Based Maximum Power Point Tracking for Grid-Tied Photovoltaic Applications Using a Z-Source Inverter," in IEEE Transactions on Power Electronics, vol. 31, no. 11, pp. 7611-7620, Nov. 2016.

[18] D. Vinnikov, A. Chub, E. Liivik and I. Roasto, "High-Performance Quasi-Z-Source Series Resonant DC-DC Converter for Photovoltaic Module-Level Power Electronics Applications," in IEEE Transactions on Power Electronics, vol. 32, no. 5, pp. 3634-3650, May 2017. 

inverter based single-phase grid-connected PV generation system with inverse Park transform PLL," 2012 IEEE International Symposium on Industrial Electronics, Hangzhou, 2012, pp. 258263.

Point Clamped Inverter for PV Applications," in IEEE Transactions on Power Electronics, vol. 32, no. 9, pp. 6700-6715, Sept. 2017.

$$
\text { H. Patel and V. Agarwal, "A Single-Stage Single-Phase Transformer-Less Doubly }
$$
Grounded Grid-Connected PV Interface," in IEEE Transactions on Energy Conversion, vol. 24, no. 1, pp. 93-101, March 2009. comparative study of single-stage inverters for a PV system." Renewable and Sustainable Energy Reviews 91 (2018): 962-986.

[23] Chakraborty, Sajib, Mohammed Mahedi Hasan, and M. Abdur Razzak. "Transformer-less single-phase grid-tie photovoltaic inverter topologies for residential application with various filter circuits." Renewable and Sustainable Energy Reviews 72 (2017): 1152-1166.

[24] Islam, Monirul, Saad Mekhilef, and Mahamudul Hasan. "Single phase transformerless inverter topologies for grid-tied photovoltaic system: A review." Renewable and sustainable energy reviews 45 (2015): 69-86.

[25] Ahmad, Zameer, and S. N. Singh. "Improved modulation strategy for single phase grid connected transformerless PV inverter topologies with reactive power generation capability." Solar Energy 163 (2018): 356-375. "Single-stage single-phase three-level neutral-point-clamped transformerless grid-connected photovoltaic inverters: Topology review." Renewable and Sustainable Energy Reviews 80 (2017): 197-214. 
[27] Rahimi, Ramin, Shahrokh Farhangi, Babak Farhangi, Gholam Reza Moradi, Ehsan Afshari, and Frede Blaabjerg. "H8 inverter to reduce leakage current in transformerless three-phase grid-connected photovoltaic systems." IEEE Journal of Emerging and Selected Topics in Power Electronics 6, no. 2 (2017): 910-918.

[28] Manash Kumar Mishra, Vivek Nandan Lal, "An improved methodology for reactive power management in grid integrated solar PV system with maximum power point condition", Solar Energy, 199 (2020): 230-245. 